\title{
The Burden, Future Trends, And Economic Impact Of Lung Cancer In Saudi Arabia
}

This article was published in the following Dove Press journal:

ClinicoEconomics and Outcomes Research

\author{
Omar B Da'ar (1D) \\ Yasmine A Zaatreh ${ }^{2}$ \\ Aida A Saad (iD ${ }^{2}$ \\ Mohammad Alkaiyat (iD ${ }^{3}$ \\ Tabrez Pasha iD $^{3}$ \\ Anwar E Ahmed (iD) \\ Rami Bustami ${ }^{4}$ \\ Khaled Alkattan (iD) ${ }^{2}$ \\ Abdul Rahman Jazieh ${ }^{3}$ \\ 'College of Public Health and Health \\ Informatics, King Saud bin Abdulaziz \\ University for Health Sciences, Riyadh, \\ Saudi Arabia; ${ }^{2}$ College of Medicine, \\ Alfaisal University, Riyadh, Saudi Arabia; \\ ${ }^{3}$ Oncology Department, King Abdulaziz \\ Medical City, National Guards Health \\ Affairs Riyadh, Riyadh, Saudi Arabia; \\ ${ }^{4}$ College of Business, Alfaisal University, \\ Riyadh, Saudi Arabia
}

Background: Incidence of cancer in Saudi Arabia has increased for the last two decades, ratcheting up to global levels. Yet, there is a dearth of research on the burden of lung cancer. This study examined the association between new cases of lung cancer and factors such as gender, age, and year of diagnosis; and forecast new cases and extrapolated future economic burden to 2030 .

Methods: This a national-level cohort study that utilized the Saudi Cancer Registry data from 1999 to 2013. Multivariate regression was used; new lung cancer cases forecast and economic burden extrapolated to 20130. Sensitivity analysis was conducted to assess the impact of a range of epidemiologic and economic factors on the economic burden.

Results: Of the 166,497 new cancer cases (1999-2013), 3.8\% was lung cancer. Males and Saudis had over threefold higher cases compared with females and non-Saudis, respectively. While the age group $\geq 65$ years had 1.14 times or $14 \%$ increase in new cases, under- 30 years had $97.2 \%$ fewer cases compared with age group 45-59. Compared with 1999, the period 2011-2013 had a $106 \%$ average increase. The years 2002-2010 registered an average 50\% rise in new cases compared to 1999 . New cases would rise to 1058 in 2030 , an upsurge of $87 \%$ from 2013 . The future economic burden was estimated at $\$ 2.49$ billion in 2015 value, of which $\$ 520$ million was attributable to care management and $\$ 1.97$ billion in lost productivity. The economic burden for the period 2015-2030 will be $\$ 50.16$ billion. The present value of this burden in 2015 values will be $\$ 34.60$ billion, of which $21 \%$ will be attributable to care management. Estimates were robust to uncertainty, but the aged-standardized rate and 5-year survival rate would account for much of the variability compared with the economic factors.

Conclusion: Findings reveal an upsurge of lung cancer burden in incidence and potential economic burden, which may inform cancer control measures.

Keywords: new cases of lung cancer, lung cancer trend, lung cancer projection, the economic burden, Saudi Arabia

\section{Introduction}

This study examined the association between new cases of lung cancer and factors such as gender, age, nationality, and year of diagnosis. Additionally, the study forecast new cases and extrapolated the economic burden of lung cancer consistent with Saudi Arabia's vision 2030. Globally, lung cancer remains one of the most commonly diagnosed and the leading cause of deaths. ${ }^{1,2}$ The motivation for this study is that although the 2013 age-standardized lung cancer incidence rate (ASR) in Saudi Arabia was lower than the global average for both males and females, 3,4 the trend in the last decade and projection in the next decade suggests a ratchet-up to the global levels, which is the highest among all cancer types.
Correspondence: Omar B Da'ar Health System Management, College of Public Health \& Health Informatics, King Saudi bin Abdulaziz University for Health Sciences, P.O. Box 22490, Riyadh II426, Saudi Arabia

Tel +966-I I-4299999 Ext. 95419

Email odaar@smumn.edu 
Despite these trends, no study, at least to our knowledge, has hitherto simultaneously examined the prediction, forecasting, and extrapolation of the economic burden of lung cancer using data from the Saudi Cancer Registry (SCR) during the period covered in this study. Recent studies ${ }^{4-6}$ were either too general, covered limited period, or did not estimate the economic burden of lung cancer.

\section{Methods}

\section{Study Design And Data}

This is a retrospective cohort study of patients and extrapolative forecasting of the future burden of lung cancer in Saudi Arabia using data from the SCR. SCR includes a nationwide record of lung cancer cases diagnosed between 1999 and 2013. There were no new cases of lung cancer reported in 2003, but an interpolation was carried based on the previous years and years after to estimate the void. While the SCR monitors the occurrence of all cancer sites in the population, 2013 was the latest available lung cancer data by the start of the present study. The SCR typically reports accurate data as part of its mandate and serves as a resource for annual reports of new cases of cancer. All health facilities in the country periodically report newly detected cases of cancer to the SCR. The SCR reports data anonymously to comply with privacy, confidentiality, and protection of patients' rights.

The data were publicly made available by SCR in aggregate form (webpage, www.chs.gov.sa). We obtained ethical approval from two independent Institutional Review Board (IRB) committees at King Abdullah International Medical Research Center and Alfaisal University, Riyadh, Saudi Arabia.

The data were collected, reviewed, and crosschecked by the study authors. Key data extracted included age, gender, nationality, and year of diagnosis. Age was classified into five groups $(<30 ; 30-44 ; 45-59 ; 60-64$; and $\geq 65$ years). The response variable, the number of new cases of lung cancer reported annually (1999-2013) was stratified according to gender, age group, nationality, and year of diagnosis.

\section{Statistical Analysis}

Statistical analysis was carried out using the STATA package (Version 13, STATA Corporation, TX, USA). The data were descriptively summarized based on demographic factors such as gender, age, and nationality, and year of diagnosis.
We employed a negative binomial regression to associate the number of new cases of lung cancer for the period 1999-2013 according to the aforementioned factors. Negative binomial regression is a technique used for modeling over-dispersed count outcome variables. Previous studies have applied these count models in healthcare. ${ }^{7,8}$ The need for count data models such as negative binomial regression was necessary because of the presence of overdispersion in the mean value of the response variable (new incidence cases). Our data indicated that the distribution of the new cases of lung cancer in each of the year of diagnosis was right-skewed and the variance higher than the mean within each level of the categories of the covariates, e.g. gender, age, and nationality. This distribution suggests the presence of over-dispersion in the data. ${ }^{9}$ We used both the unadjusted and adjusted incidence rate ratios (IRR and aIRR, respectively) for negative binomial regression, and $95 \%$ confidence intervals $(95 \% \mathrm{CI})$ to establish the strength of the association of the variables of interest. In the interest of space, we only report the adjusted IRR. Statistical significance was considered at $\mathrm{p}<0.05$.

\section{Forecasting And Projection Of New Lung Cancer Cases}

Additionally, we carried out forecasting of new cases of lung cancer by predicting the 2015-2030 cases based on the numbers of 1999-2013. Data for 2014 were unavailable at the time of collection, hence extrapolation was to fill the void. We modeled new cases of lung cancer in relation to year of diagnosis. We constructed a trend line because the reported cases showed an upward movement. Thus, we forecast the historical numbers by adding a trend line to allow for the estimation of future cases. Thus, the trend and forecasting generated a regression line of best fit for future values. Due to the linearity of data, the possibility of the regression line exhibiting other non-linearity characteristics was ruled out.

\section{Extrapolation Of Lung Cancer Costs}

We used epidemiologic and economic data from Saudi Arabia, comparable regional and international countries to extrapolate and estimate lung cancer costs. Extrapolations of the economic burden of diseases have been used in health economic evaluations. ${ }^{10,11}$ In the absence of long-term data such as direct costs and lost productivity associated with a disease, temporal extrapolation over a longer time horizon is required. $^{12}$ For international comparisons, we used 
purchasing power parity (PPP), a measure of the ratio of the prices in national currencies of the same good or service in different countries at the same point in time. ${ }^{13} \mathrm{PPP}$ for health in Saudi Arabia was not available and therefore we used the PPP of the general economy. Integrating PPP into cost-ofdisease studies provides a greater understanding of healthcare comparisons across countries. ${ }^{14}$ In these kinds of adjustments and international comparisons, the USA provides the ideal data primarily for two reasons: firstly, health expenditures per capita converted to USD PPPs are, in fact, among the most frequently quoted indicators and usually presented in the form of a country ranking. ${ }^{15}$ Secondly, the USA has predominantly privately produced healthcare system where purchases are not only relevant, but price indexes are used to create constant price output measures for medical services. ${ }^{14}$ Productivity changes are often ignored in countries where health care provided by the public sector. ${ }^{14}$ Since health care in Saudi Arabia is largely financed by the public sector, the country will greatly benefit from such international comparisons.

\section{Sensitivity Analysis}

We used sensitivity analysis to assess the impact of a range of economic and epidemiologic factors on the economic burden of lung cancer. These factors included ASR, nonhealth GDP per capita, 5-year survival rate, health expenditure as a share of GDP, and discount rate. The absence of reliable standard data on which to base economic evaluation and the existence of a range of estimates for the factors or parameters used compels one to account for uncertainty. ${ }^{16}$ Such estimation and methodology are emphasized in health economic models. ${ }^{17}$

\section{Results}

\section{Descriptive Statistics}

Out of the total of 166,497 cancer incident cases that were diagnosed and analyzed from 1999 to 2013 in Saudi Arabia, 6404 (3.8\%) were new cases of lung cancer. Nearly three-fourths (76.4\%) of the sample diagnosed with lung cancer were male, while $58.9 \%$ of the cases were aged 60 years and older. Table 1 shows these descriptive statistics.

\section{Regression Results}

Table 2 provides the IRR estimates of the multivariate negative binomial regression. Adjusting for other factors, the model revealed that males had over threefold higher lung
Table I Characteristics Of Patients Diagnosed With Lung Cancer In Saudi Arabia, 1999-2013 (N=6404)

\begin{tabular}{|l|l|l|l|}
\hline & Factor & $\mathbf{N}$ & $\%$ \\
\hline Year & 1999 & 294 & 4.8 \\
& 2000 & 270 & 4.4 \\
& 2001 & 194 & 3.2 \\
& 2002 & 297 & 4.9 \\
& 2003 & 328 & 5.4 \\
& 2004 & 359 & 5.9 \\
& 2005 & 455 & 7.5 \\
& 2006 & 431 & 7.1 \\
& 2007 & 534 & 8.8 \\
& 2008 & 469 & 7.7 \\
& 2009 & 490 & 8.1 \\
& 2010 & 520 & 8.6 \\
& 2011 & 587 & 9.7 \\
& 2012 & 611 & 10.1 \\
& 2013 & 565 & 9.3 \\
\hline Gender & Female & 1,511 & 23.6 \\
& Male & 4,893 & 76.4 \\
\hline \multirow{5}{*}{ Age } & $<30$ years & 134 & 2.1 \\
& $30-344$ years & 596 & 9.3 \\
& $45-59$ years & 1,902 & 29.7 \\
& $60-64$ years & 935 & 14.6 \\
& $\geq 65$ years & 2,837 & 44.3 \\
\hline & Non-Saudi & 1,479 & 23.1 \\
& Saudi & 4,925 & 76.9 \\
\hline
\end{tabular}

cancer incidence compared with females (aIRR $=3.13,95 \%$ CI, 2.843 to 3.447, p $<0.001$ ). Greater number of new cases of lung cancer was also associated with Saudis compared with non-Saudis (aIRR $=3.10,95 \%$ CI, 2.810 to $3.429, \mathrm{P}<$ 0.001 ). However, the reported cases were found to be greatest among the age group $\geq 65$ years with 1.14 times or $14 \%$ increase in new cases (aIRR $=1.140,95 \% \mathrm{CI}, 1.001$ to 1.299 , $\mathrm{P}<0.048$ ) compared with $45-59$ years. The age group under 30 years had $97.2 \%$ (1-0.028) fewer cases compared with patients aged 45-59 years. Additionally, the results revealed that while there was a $20 \%$ average decline in the number of new cases over the 2000-2001 periods, the years 2011-2013 witnessed a $106 \%$ average increase compared with the year 1999. Other intervening years (2002-2010) registered a 50\% average increase in new cases compared with the year 1999.

\section{Forecasting Lung Cancer Cases}

There were 565 new lung cancer cases identified in 2013, up from 294 new cases reported in 1999, an increase of $92 \%$ over a $14-$ year period. Further analysis showed that 
Table 2 Association Between New Cases Of Lung Cancer And Gender, Nationality, Age, And Year Of Diagnosis

\begin{tabular}{|c|c|c|c|c|c|c|}
\hline \multirow[t]{2}{*}{ Cases } & \multirow[t]{2}{*}{ alRR } & \multirow[t]{2}{*}{ Robust Std. Errors } & \multirow[t]{2}{*}{$\mathbf{Z}$} & \multirow[t]{2}{*}{$\mathbf{P}>\mathbf{z}$} & \multicolumn{2}{|c|}{ 95\% Wald Conf. Interval For alRR } \\
\hline & & & & & Lower & Upper \\
\hline Constant & 2.138 & 0.253 & 6.410 & $<0.001 *$ & 1.694 & 2.697 \\
\hline \multicolumn{7}{|c|}{ Gender $($ female $=$ reference $)$} \\
\hline Male & 3.130 & 0.154 & 23.250 & $<0.001 *$ & 2.843 & 3.447 \\
\hline \multicolumn{7}{|c|}{ Nationality (non-Saudi = reference) } \\
\hline Saudi & 3.104 & 0.158 & 22.320 & $<0.001 *$ & 2.810 & 3.429 \\
\hline \multicolumn{7}{|c|}{ Age group (age $45-59=$ reference) } \\
\hline Age $<30$ & 0.028 & 0.003 & -30.310 & $<0.001$ & 0.022 & 0.035 \\
\hline Age $30-44$ & 0.274 & 0.023 & -15.540 & $<0.001$ & 0.233 & 0.322 \\
\hline Age $60-64$ & 0.840 & 0.049 & -2.990 & $0.003 *$ & 0.750 & 0.942 \\
\hline Age $\geq 65$ & 1.140 & 0.076 & 1.980 & $0.048^{*}$ & 1.001 & 1.299 \\
\hline \multicolumn{7}{|c|}{ Year of diagnosis (1999 = reference) } \\
\hline 2000 & 0.892 & 0.126 & -0.810 & 0.419 & 0.676 & I.I77 \\
\hline 2001 & 0.708 & 0.116 & -2.110 & $0.035^{*}$ & 0.513 & 0.976 \\
\hline 2002 & 1.054 & 0.146 & 0.380 & 0.707 & 0.802 & 1.384 \\
\hline 2004 & 1.192 & 0.149 & 1.400 & 0.160 & 0.933 & 1.523 \\
\hline 2005 & 1.671 & 0.221 & 3.890 & $<0.00 I^{*}$ & 1.290 & 2.165 \\
\hline 2006 & 1.574 & 0.212 & 3.360 & $0.001 *$ & 1.209 & $2.05 I$ \\
\hline 2007 & 1.810 & 0.234 & 4.600 & $<0.00 I^{*}$ & 1.406 & 2.331 \\
\hline 2008 & 1.534 & 0.194 & 3.380 & $0.001 *$ & I.197 & 1.966 \\
\hline 2009 & 1.778 & 0.226 & 4.530 & $<0.001 *$ & 1.386 & 2.281 \\
\hline 2010 & 1.850 & 0.232 & 4.910 & $<0.00 I^{*}$ & $\mathrm{I} .447$ & 2.366 \\
\hline 2011 & 2.024 & 0.278 & 5.130 & $<0.00 I^{*}$ & 1.546 & 2.650 \\
\hline 2012 & 2.152 & 0.282 & 5.840 & $<0.00 I^{*}$ & 1.664 & 2.782 \\
\hline 2013 & 2.013 & $0.25 I$ & 5.620 & $<0.00 I^{*}$ & 1.577 & 2.570 \\
\hline
\end{tabular}

Notes: *Significant at $\alpha=0.05$.

Abbreviation: aRR, adjusted incidence rate ratios.

the forecast lung cancer cases would increase to 1058 by the year 2030, a rise of $87 \%$ from the 2013 cases. Figure 1 shows the historical cases and forecasting.

\section{Extrapolation Of Cost Of Lung Cancer}

In addition to examining the association of lung cancer cases and gender, age, nationality, and year of diagnosis, we carried out an extrapolation of the cost of lung cancer using economic data and epidemiologic assumptions from Saudi Arabia, comparable regional countries, and international data. Extrapolation has been used in health economic evaluations. ${ }^{10,11}$ Temporal extrapolation over a longer time horizon is required, ${ }^{12}$ especially when long-term data such as direct costs and lost productivity associated with a disease are not available.
We adjusted lung cancer cost attributable to care management and the potential lost productivity of the United States for the respective ratios of ASR, 5-year survival rate, and healthcare expenditure as a share of gross domestic product (GDP) of Saudi Arabia and the USA. We further adjusted the burden for uncertainty.

Total lung cancer burden was estimated to be $\$ 2.49$ billion in 2015, of which $\$ 520$ million was attributable to care management and $\$ 1.97$ billion in potential lost productivity. The care management cost of $\$ 520$ million was obtained by multiplying 0.155 , the ratio of the respective ASR, by 0.726 , the ratio of respective PPP; 0.345 , the ratio of respective healthcare expenditure as a share of gross domestic product (GDP); and \$13.4 billion, the 2015 USA lung cancer costs attributable to care management. The potential lost productivity of $\$ 1.97$ billion was obtained by 


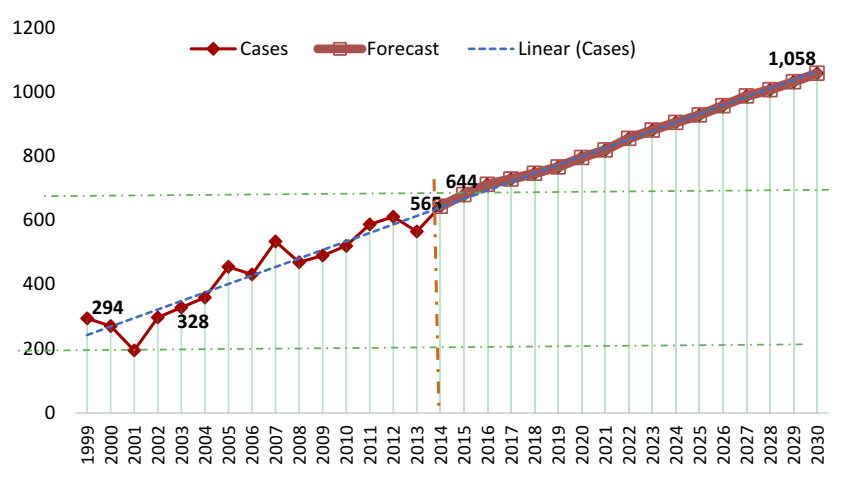

Figure I Lung cancer cases (1999-2013), trend, and forecast (2014-2030) in Saudi Arabia. The cases were summarized from the national-level cohort report utilizing data from the Cancer Registry of Saudi Arabia. The figure depicts a line that best fits the data.

multiplying 0.155 , the ratio of the respective ASR, 0.726 , the ratio of respective PPP; 0.417 , the ratio of respective nonhealth gross domestic product (GDP) per capita healthcare expenditure as share of gross domestic product (GDP); 2.33, the ratio of respective of 5-year survival rate (USA: Saudi Arabia); 0.5, a risk-adjustment factor; and $\$ 36.1$ billion, the 2015 USA lung cancer-related lost productivity. The 5-year lung cancer survival rates for the two countries were reviewed in previous studies. ${ }^{18}$ Since Saudi Arabia had lower 5-year survival rate, it implies a lower cost of lung cancer care management and higher lost productivity. Table 3 shows the parameterization and assumptions used.
We carried out additional extrapolation in order to compute the future and present values of lung cancer costs for the period 2015-2030 with the assumption that the future total estimated lung cancer cost in Saudi Arabia will increase proportionally to the growth of the forecast of lung cancer cases. The average growth of lung cancer cases during the 2015-2030 periods is calculated at $3 \%$.

At the same time, the future costs were discounted at $5 \%$ in order to calculate their present value (PV). The PV is premised on the assumption of the time value of money. Thus, future extrapolated total burden of lung cancer (combined cost of care management and lost productivity) in the period 2015-2030 would be $\$ 50.17$ billion, of which $\$ 10.50$ is expected to be related to care management and $\$ 39.67$ billion in lost productivity. However, in present value (i.e. in 2015 values), lung cancer burden will be $\$ 34.60$ billion, of which $\$ 7.24$ is expected to be related to care management and $\$ 27.36$ in lost productivity. Table 4 shows these results.

\section{Sensitivity Analysis}

Table 5 indicates the burden of lung cancer (combined cost of care management and lost productivity) of $\$ 34.61$ billion over the 2015-2030 horizon. This is the base case scenario. A 20\% reduction in ASR, non-health GDP per

Table 3 Extrapolation Of Lung Cancer Cost In Saudi Arabia

\begin{tabular}{|l|l|l|}
\hline Computed Values And Parameter Assumptions & Values & Sources \\
\hline ASR/I00,000, Saudi Arabia & 5.6 & Literature \\
ASR/I00,000, United States & 36.1 & American Lung Cancer Association \\
ASR/I00,000 (I994-20I5) average annual growth, Saudi Arabia & $3 \%$ & Authors' compilation from literature \\
5-year survival rate, Saudi Arabia & $8 \%$ & Salim, et al (20II) I8 \\
5-year survival rate, United States & $18.6 \%$ & American Lung Cancer/NCl \\
Purchasing Power Parity (PPP) Conversion, Saudi Arabia & 1.378 & World Bank \\
Purchasing Power Parity Conversion, United states & 1 & World Bank \\
Lung cancer cost (20I5), United states & $\$ 13.4$ & NCl, NIH \\
Lung cancer lost productivity (20I5), United states & $\$ 36.1$ & NCl, NIH \\
Healthcare expenditure as \% of GDP, United states & $16.8 \%$ & World Bank \\
Healthcare expenditure as \% of GDP, Saudi Arabia & $5.8 \%$ & World Bank \\
Health expenditure per capita, United States & $\$ 9,536$ & World Bank \\
Health expenditure per capita, Saudi Arabia & $\$ 1,194$ & World Bank \\
GDP per capita, United States & $\$ 56,444$ & World Bank \\
GDP per capita, Saudi Arabia & $\$ 20,733$ & World Bank \\
Non-health GDP per capita, United States & $\$ 46,908$ & Authors' computation \\
Non-health GDP per capita, Saudi Arabia & Authors' computation \\
Certainty factor & $\$ 19,539$ & Literature \\
Estimated cost lung cancer care management cost (20I5), Saudi Arabia & 0.5 & Authors' computation \\
Estimated lung cancer lost productivity (20I5), billions, Saudi Arabia & $\$ 0.52$ & Authors' computation \\
Total estimated lung cancer burden (20I5), billions Saudi Arabia & $\$ 3.15$ & Authors' computation \\
\hline
\end{tabular}


Table 4 Future And Present Value Estimated Cost Of Lung Cancer Care Management And Productivity Loss

\begin{tabular}{|c|c|c|c|c|c|}
\hline \multicolumn{2}{|l|}{ Year } & \multicolumn{2}{|c|}{ Cancer Care Management } & \multicolumn{2}{|l|}{ Productivity Loss } \\
\hline & & $\begin{array}{l}\text { Cost (\$ millions) } \\
\text { Undiscounted \& 3\% } \\
\text { Incidence Growth }\end{array}$ & $\begin{array}{l}\text { Cost (\$ millions) In } \\
2015 \text { Values \& } \\
\text { Discounted At } 5 \% \text { Rate }\end{array}$ & $\begin{array}{l}\text { Cost (\$ millions) } \\
\text { Undiscounted \& 3\% } \\
\text { Incidence Growth }\end{array}$ & $\begin{array}{l}\text { Cost (\$ millions) In } \\
20 \text { I5 Values \& } \\
\text { Discounted At 5\% Rate }\end{array}$ \\
\hline Beginning year $=0$ & 2015 & 520 & 520 & 1970 & 1970 \\
\hline 1 & 2016 & 540 & 510 & 2030 & 1930 \\
\hline 2 & 2017 & 550 & 500 & 2090 & 1890 \\
\hline 3 & 2018 & 570 & 490 & 2150 & 1860 \\
\hline 4 & 2019 & 590 & 480 & 2210 & 1820 \\
\hline 5 & 2020 & 600 & 470 & 2280 & 1790 \\
\hline 6 & 2021 & 620 & 460 & 2350 & 1750 \\
\hline 7 & 2022 & 640 & 460 & 2420 & 1720 \\
\hline 8 & 2023 & 660 & 450 & 2490 & 1690 \\
\hline 9 & 2024 & 680 & 440 & 2570 & 1660 \\
\hline 10 & 2025 & 700 & 430 & 2640 & 1620 \\
\hline II & 2026 & 720 & 420 & 2720 & 1590 \\
\hline 12 & 2027 & 740 & 410 & 2810 & 1560 \\
\hline 13 & 2028 & 760 & 410 & 2890 & 1530 \\
\hline 14 & 2029 & 790 & 400 & 2980 & 1500 \\
\hline 15 & 2030 & 810 & 390 & 3070 & 1470 \\
\hline Total & & 10,500 & 7240 & 39,670 & 27,360 \\
\hline
\end{tabular}

Notes: Years - represent time and depict the number of years from the beginning year/current year 0, i.e. 20I5 to I5, the end of forecasting period (2030).

capita, and health expenditure as a share of GDP would decrease the base total estimated burden by $\$ 7.42$ billion, $\$ 5.47$ billion, and $\$ 1.45$ billion respectively. A $20 \%$ increase in these factors adds to the total burden $\$ 8.03$ billion, $\$ 5.47$ billion, and $\$ 1.45$ billion, respectively, during the same period.
Allowing discount rate and 5-year survival rate to vary in a similar fashion produces opposite effects, i.e. a $20 \%$ reduction in these factors would increase the total estimated burden by $\$ 2.47$ billion and $\$ 6.84$ billion, respectively. However, a $20 \%$ increase in these two factors would decrease the estimated burden.

Table 5 Sensitivity And Adjusted Sensitivity Of Lung Cancer Burden (\$ billions) (20I5-2030)

\begin{tabular}{|c|c|c|c|c|c|c|}
\hline & Variability & ASR & $\begin{array}{l}\text { Non-Health GDP Per } \\
\text { Capita }\end{array}$ & $\begin{array}{l}\text { Discount } \\
\text { rate }\end{array}$ & $\begin{array}{l}\text { 5-Year Survival } \\
\text { Rate }\end{array}$ & $\begin{array}{l}\text { Health Expenditure \% } \\
\text { GDP }\end{array}$ \\
\hline & Panel A & \multicolumn{5}{|c|}{ Parameter assumptions and base values } \\
\hline A & $20 \%$ Reduction & 4.4 & $\$ 15,63 \mid$ & $4.0 \%$ & $6 \%$ & $4.6 \%$ \\
\hline B & Base scenario & 5.6 & $\$ 19,539$ & $5.0 \%$ & $8 \%$ & $5.8 \%$ \\
\hline \multirow[t]{2}{*}{ C } & $20 \%$ Increase & 6.9 & $\$ 23,447$ & $6.0 \%$ & $10 \%$ & $7.0 \%$ \\
\hline & Panel B & \multicolumn{5}{|c|}{ Sensitivity analysis } \\
\hline D & $20 \%$ Reduction & $\$ 27.19$ & $\$ 29.13$ & $\$ 37.07$ & $\$ 41.45$ & $\$ 33.16$ \\
\hline E & Base scenario & $\$ 34.61$ & $\$ 34.61$ & $\$ 34.61$ & $\$ 34.61$ & $\$ 34.61$ \\
\hline \multirow[t]{2}{*}{$\mathrm{F}$} & $20 \%$ Increase & $\$ 42.64$ & $\$ 40.08$ & $\$ 32.39$ & $\$ 30.04$ & $\$ 36.05$ \\
\hline & Panel C & \multicolumn{5}{|c|}{ Adjusted sensitivity analysis } \\
\hline$G=(D-E)$ & $20 \%$ Reduction & $-\$ 7.42$ & $-\$ 5.47$ & $\$ 2.47$ & $\$ 6.84$ & $-\$ 1.45$ \\
\hline $\mathrm{H}$ & Base scenario & - & - & - & - & - \\
\hline $\mathrm{I}=(\mathrm{F}-\mathrm{E})$ & $20 \%$ Reduction & $\$ 8.03$ & $\$ 5.47$ & $-\$ 2.22$ & $-\$ 4.56$ & $\$ 1.45$ \\
\hline $\mathrm{J}=\mathrm{Abs}(\mathrm{G}-\mathrm{l})$ & Range & $\$ 15.45$ & $\$ 10.95$ & $\$ 4.69$ & $\$ 11.40$ & $\$ 2.90$ \\
\hline $\mathrm{K}=$ Rank of $\mathrm{J}$ & Rank & I & 3 & 4 & 2 & 5 \\
\hline
\end{tabular}




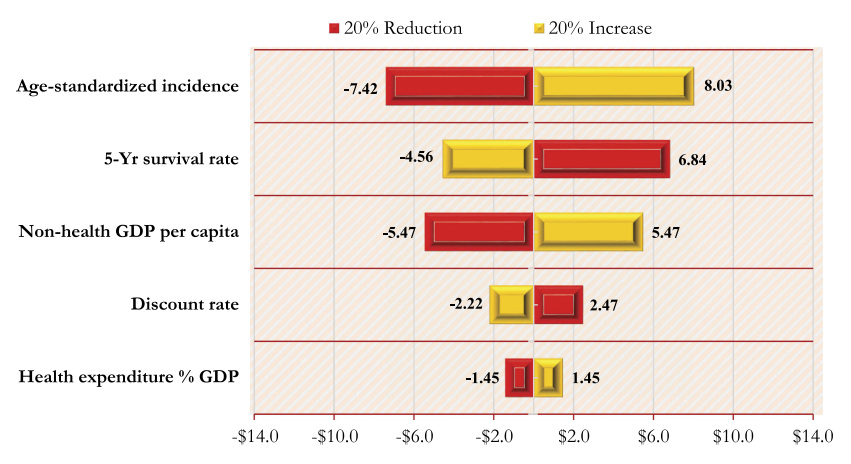

Figure 2 A Tornado diagram depicting the sensitivity of estimated burden of lung cancer ( $\$$ billions) with respect to epidemiologic and economic factors.

It is evident from the above sensitivity analysis that the burden of lung cancer change when different parameter assumptions are taken into consideration (20\% reduction and $20 \%$ increase). However, while there is a decrease or increase in the total costs below or above the base value, the changes do not significantly influence the actual estimates, suggesting that the results are robust to the different parameter assumptions in estimating the burden of lung cancer.

Figure 2 shows the sensitivity of the estimated burden of lung cancer ( $\$$ billions) both in terms of cost of care management and lost productivity with respect to epidemiologic and economic factors. ASR and 5-year survival rate would account for much of the variability, while less variability would be attributable to the discount rate and health expenditure as a share of GDP.

\section{Discussion}

By retrospectively reviewing a cohort of patients diagnosed with lung cancer from 1999 and 2013, the present study examined the association between new cases of lung cancer and gender, age, nationality, and year of diagnosis. Additionally, the study forecast the new cases to 2030 while extrapolating on the future economic burden.

Both the descriptive statistics and multivariate analysis suggest that for the 14-year period from 1999 to 2013, males had over threefold higher lung cancer cases compared with females. These findings are consistent with reported low ASR of lung cancer and the general population trends and challenges of lung cancer, ${ }^{19-21}$ particularly in Saudi Arabia ${ }^{6}$ and the Middle East and North Africa. ${ }^{22}$ Studies show lung cancer incidence rates among men in the United States, Canada, England, Denmark, and Australia had peaked by 2005, but they continue to rise in Spain, People's Republic of China, and Japan. ${ }^{23}$ However, among women, although rates have been considerably lower, they appeared to be on an upward trend. $^{24} \mathrm{~A}$ recent study on the European cancer mortality predictions for the year 2017 showed that lung cancer rates among men are predicted to decline $10.7 \%$ since 2012, while those of women are expected to wane. ${ }^{25}$ Elsewhere in Europe, the trend is similar. ${ }^{26}$

Compared with the age group 45-59 years, while the age group $\geq 65$ years were associated with the greatest number of new cases of lung cancer, the under 30 years were found to have fewest cases. A recent unpublished thesis indicates lung cancer is rarely diagnosed among people under 30 years of age in Saudi Arabia, but the incidence rises sharply thereafter peaking in the 65-69 years age group. ${ }^{6}$ Another recent overview analysis revealed a higher mean age at diagnosis in deceased patients compared with those who survived. ${ }^{4}$ This result is consistent with previous reports, which indicated that increasing population and longevity may potentially add to the incidence of lung cancer. ${ }^{19-22}$ For example, studies show that one or two out of every 100 men who are 60 years old today will get lung cancer by the age of $70^{27}$ and lung cancer incidence rates have increased overall in most adult age groups with rates being significantly higher among seniors. ${ }^{28}$ Moreover, lung cancer incidence has been shown to be strongly related to age, with the highest incidence among older people. In the UK, on average each year more than four in $10(44 \%)$ of new cases were in people aged 75 and above during 2013-2015. ${ }^{28}$

A comprehensive review of epidemiology, etiology, and prevention of lung cancer suggest that although smoking prevalence is lowest among individuals aged 65 years and older (9.3\%) compared with those aged 18-24 years $(21.4 \%), 25-44$ years $(23.7 \%)$, and $45-64$ years $(22.6 \%)$, more than $65 \%$ of patients with lung cancer are older than $65 .{ }^{29}$ These results are also consistent with the predictions that lung cancer will continue to be a major cause of death worldwide within the foreseeable future, particularly due to the aging of the global population. $^{30}$

The findings further suggest that while there were lower new cases of lung cancer over the 2000-2001 periods, the years 2011-2013 witnessed an average increase compared with the year 1999. Overall, there appeared to be a rise in new cases of lung cancer in the latter years compared with the year 1999. These results appear to be consistent with the trends where there was an increase of $92 \%$ over the 14 -year period (1999-2013). Our analysis further shows that lung cancer incidence cases are projected to rise a further $87 \%$ by the year 2030 up from the 2013 estimates. These findings are 
in tandem with trends elsewhere across the globe. For example, in the UK lung cancer incidence rates for males and females combined increased by 3\% between 2003-2005 and 2013-2015. ${ }^{28}$ These results are also consistent with predictions indicating that estimated lung cancer will be the sixth most common cause of death by $2030 .{ }^{31}$ However, an analysis of the changing epidemiology of lung cancer in the United States over the last 30 years showed a negative trend in lung cancer. ${ }^{32}$

Our study suggests adjusted incidence rate of lung cancer may be related to nationality where the rates among Saudis were found to be higher compared with non-Saudi population in the Kingdom. While this result may be intuitive given that Saudis cases comprised $76 \%$ of the sample, it may be linked to literature on race and ethnicity differentials in lung cancer observed in other countries. For example, studies showed that the incidence of lung cancer is substantially higher among blacks and Native Hawaiians and other Polynesians and lower among Japanese Americans and Hispanics than among whites in the United States. $^{33}$ Additionally, a multi-ethnic cohort study showed that black Americans and Native Hawaiians had a significantly greater risk for lung cancer compared with whites. ${ }^{34}$ Further, a case-control study showed that first-degree relatives of blacks have a greater risk of early-onset lung cancer than their white counterparts, although cumulative differences in risk for lung cancer among blacks and whites are further amplified by increasing cigarette smoking exposure. $^{35}$

The extrapolation of the significant estimated burden of lung cancer both in terms of care management and potential lost productivity appeared consistent with trends in high-income countries. ${ }^{36}$ In particular, our study suggests lung cancer-related potential lost productivity will account for $79 \%$ of the total estimated lung cancer burden. While lung cancer incidence is still relatively low in Saudi Arabia, the growing burden may potentially limit gains in health outcomes such as increased life expectancy. The results may also point to the direction of high-burden countries where lung cancer cost attributable to lost productivity represents between $37 \%$ and $82 \%$ of the total cost of the disease. ${ }^{37,38}$

Our study simultaneously evaluated the forecasting of both the dynamics of incidence and burden of lung cancer consistent with Saudi Arabia's vision 2030. Thus, the study contributes to the understanding of the upsurge of the disease incidence and its potential economic burden, issues that are rarely studied but which we believe can guide cancer control measures and management. That said, it should be noted that the study has limitations. Our analysis utilized data from SCR where such records may be prone to lack of harmonization from the various sources that feed the registry. This may lead to underestimation of the incidence of all primary lung cancer cases. Thus, there is a need to consider additional data from primary sources. Additionally, the extrapolation of the burden of lung cancer in terms of both the cost of care management and lost productivity was in part dependent on a variety of parameter assumptions derived from epidemiologic and economic data from comparable regional and international sources. Although sensitivity analysis was carried out to apportion sources of uncertainty or variability present in the data, the mere use of extrapolation may itself yield more nuanced results that require careful interpretation.

\section{Conclusion}

The present study examined historical lung cancer incidence cases, future trends, and potential economic burden in Saudi Arabia and the association between the incidence of lung cancer cases and factors such as gender, age, nationality, and year of diagnosis. The study findings suggest that males were more than females diagnosed with lung cancer by as much as two to three times. Compared with middleaged patients, the analysis additionally revealed that while seniors ( $\geq 65$ years) were significantly associated with the greatest incidence, the under 30 age group was associated with the lowest. Moreover, the results suggested that while incidence cases of lung cancer were higher in the latter years covering the data, forecasting to 2030 will increase the rates by as much as $87 \%$ from the 2013 estimates.

The findings and conclusion of our paper may well inform healthcare practitioners, policymakers, and researchers about the management of cancer. In this regard, we believe the findings will have implications for cancer registries, especially on the management of lung cancer and by extension all other cancer types. All data cases from primary sources must be harmonized by verifying thoroughly and regularly upon reception and at the level of official publication. Such verification will, for instance, help in the validation of our result, which suggested higher new cases of lung cancer in the latter years covering the data. As it is, we cannot ascertain whether such increases in the latter years were merely due to improved reporting and automation, or sheer upsurge in the incidence of lung cancer. The verification and harmonization process can be done collaboratively with experts 
from research institutions, universities, and relevant Ministries such as the Ministry of Health and National Guard Health Affairs. This may help in the triangulation of data and further reinforce the veracity of the data sources.

Based on our findings and conclusion, we offer recommendations that we believe will spur future research. For instance, our study suggested that males were more than females diagnosed with lung cancer by as much as two to three times. While this may be consistent with findings elsewhere, the result or data may be confounded by context or cultural-specific issues that bias gender differentials not only on health but social matters as well. Thus, there is a need for further research that isolates cancer registry-specific practice style as natural experiments in order to assess the comparative effectiveness of different registries of the country or region with a view to scrutinizing the possible underreporting of women cancer incidence rates. The enormous reported burden of lung cancer underscores the urgent need for containing cancer controls and prioritization of research.

\section{Ethics Approval And Informed Consent}

We obtained ethical approval from two independent Institutional Review Board (IRB) committees at King Abdullah International Medical Research Center, King Abdulaziz Medical City, Riyadh, Saudi Arabia and Alfaisal University, Riyadh under the protocol number R17/114/R. The data were publicly available at Saudi Cancer Registry (webpage, www.chs.gov.sa), and obtained access by research proposal and IRB approval. No informed consent was necessary.

\section{Data Availability}

The data are publicly available at Saudi Cancer Registry (webpage, www.chs.gov.sa), but can only be obtained by research proposal and IRB approval.

\section{Acknowledgment}

The authors would like to express their thanks and gratitude to King Abdullah International Medical Research Centre (KAIMRC) and Alfaisal University for the support and IRB approval (code R17/114/R).

\section{Disclosure}

All authors have no conflicts of interest to declare in this work.

\section{References}

1. Ferlay J, Soerjomataram I, Dikshit R, et al. Cancer incidence and mortality worldwide: sources, methods and major patterns in GLOBOCAN 2012. Int $J$ Cancer. 2015;136(5):E359-E386. doi:10. 1002/ijc. 29210

2. Jemal A, Bray F, Center MM, Ferlay J, Ward E, Forman D. Global cancer statistics. CA Cancer J Clin. 2011;61(2):69-90. doi:10.3322/ caac. 20107

3. Saudi Health Council. Cancer Incidence Report. The National Saudi Cancer Registry, Riyadh, Saudi Arabia; 2013.

4. Alghamdi HI, Alshehri AF, Farhat GN. An overview of mortality \& predictors of small-cell and non-small cell lung cancer among Saudi patients. J Epidemiol Glob Health. 2017.

5. Ibrahim E, Bin SB, Banjar L, Awadalla S, Abomelha MS. Current and future cancer burden in Saudi Arabia: meeting the challenge. Hematol Oncol Stem Cell Ther. 2008;1(4):210-215. doi:10.1016/S1658-3876 (08)50006-9

6. Alzahrani S Modelling and forecasting lung cancer incidence and mortality in Saudi Arabia [PhD]. Manchester, UK: University of Salford; 2016.

7. Sari N. Physical inactivity and its impact on healthcare utilization. Health Econ. 2009;18(8):885-901. doi:10.1002/hec.v18:8

8. Grootendorst PV. A comparison of alternative models of prescription drug utilization. Health Econ. 1995;4(3):183-198. doi:10.1002/(ISSN)10991050

9. Weaver CG, Ravani P, Oliver MJ, Austin PC, Quinn RR. Analyzing hospitalization data: potential limitations of Poisson regression. Nephrol Dial Transplant. 2015;30(8):1244-1249. doi:10.1093/ndt/ gfv071

10. Van Houtven G, Honeycutt AA, Gilman B, McCall NT, Throneburg WW, Sykes KE. Costs of Illness among Older Adults: An Analysis of Six Major Health Conditions with Significant Environmental Risk Factors. Research Triangle Park, RTI Press, NC. 2008 Sep. RTI Press Research Report Series.

11. Beyene TJ, Mourits MCM, Kidane AH, Hogeveen H. Estimating the burden of rabies in Ethiopia by tracing dog bite victims. PLoS One. 2018;13(2):e0192313. doi:10.1371/journal.pone.0192313

12. Bojke L, Manca A, Asaria M, Mahon R, Ren S, Palmer S. How to appropriately extrapolate costs and utilities in cost-effectiveness analysis. Pharmacoeconomics. 2017;35(8):767-776. doi:10.1007/s402 73-017-0512-6

13. Schreyer P, Koechlin F. Purchasing Power Parities 1999 Benchmark Results. Organization for Economic Co-operation and Development; 2002. Available from: http://www.oecd.org/pdf/M00028000/ M00028875.pdf. Accessed November 4, 2019.

14. Triplett JE. Integrating cost-of-disease studies into purchasing power parities : A Disease-Based Comparison of Health Systems. OECD, Paris, 2003:131.

15. Huber M. International Comparisons of Prices and Volumes in Health Care among OECD Countries. Austria: European Center for Social Welfare Policy and Research; 2006.

16. Levin HM, McEwan PJ. Cost-Effectiveness Analysis: Methods and Applications. Thousand Oaks, CA: Sage Publications Inc.; 2000:328pp.

17. Drummond MF, Sculpher MJ, Claxton K, Stoddart GL, Torrance GW. Methods for the Economic Evaluation of Health Care Programmes. Oxford university press; 2015.

18. Salim EI, Jazieh AR, Moore MA. Lung cancer incidence in the arab league countries: risk factors and control. Asian Pac J Cancer Prev. 2011;12(1):17-34. 
19. Mourshed M, Hediger V, Lambert T. Gulf cooperation council health care: challenges and opportunities. Global competitiveness reports. 2006.

20. Ng M, Freeman MK, Fleming TD, et al. Smoking prevalence and cigarette consumption in 187 countries, 1980-2012. JAMA. 2014;311 (2):183-192. doi:10.1001/jama.2013.284692

21. World Health Organization. WHO Report on the Global Tobacco Epidemic 2015: Raising Taxes on Tobacco: World Health Organization. Geneva, Switzweland: World Health Organization; 2015.

22. Roudi F. Population Trends and Challenges in the Middle East and North Africa. Washington, DC: Population Reference Bureau; 2001.

23. Parkin DM, Bray F, Devesa S. Cancer burden in the year 2000. The global picture. Eur J Cancer. 2001;37:4-66. doi:10.1016/S0959-8049 (01)00267-2

24. Devesa SS, Bray F, Vizcaino AP, Parkin DM. International lung cancer trends by histologic type: male: female differences diminishing and adenocarcinoma rates rising. Int J Cancer. 2005;117(2):294299. doi:10.1002/(ISSN)1097-0215

25. Malvezzi M, Carioli G, Bertuccio P, et al. European cancer mortality predictions for the year 2017, with focus on lung cancer. Ann Oncol. 2017;28(5):1117-1123. doi:10.1093/annonc/mdx033

26. Medenwald D, Vordermark D, Dietzel CT. Cancer mortality in former East and West Germany: a story of unification? BMC Cancer. 2017;17(1):94. doi:10.1186/s12885-017-3086-y

27. Howlader N, Noone A, Krapcho M, et al. SEER Cancer Statistics Review, 1975-2012. Bethesda: National Cancer Institute; Journal 2015.

28. Cancer registration statistics, England. Cancer Diagnoses and Age-Standardised Incidence Rates for All Types of Cancer by Age and Sex. Office for National Statistics,London, UK, First Release. 2016.
29. Dela Cruz CS, Tanoue LT, Matthay RA. Lung cancer: epidemiology, etiology, and prevention. Clin Chest Med. 2011;32(4):605-644. doi:10.1016/j.ccm.2011.09.001

30. Youlden DR, Cramb SM, Baade PD. The international epidemiology of lung cancer: geographical distribution and secular trends. J Thoracic Oncol. 2008;3(8):819-831. doi:10.1097/JTO.0b013e31818020eb

31. Mathers CD, Loncar D. Projections of global mortality and burden of disease from 2002 to 2030. PLoS Med. 2006;3(11):e442. doi:10.1371/ journal.pmed.0030442

32. Govindan R, Page N, Morgensztern D, et al. Changing epidemiology of small-cell lung cancer in the United States over the last 30 years: analysis of the surveillance, epidemiologic, and end results database. J Clin Oncol. 2006;24(28):4539-4544. doi:10.1200/JCO.2005.04.4859

33. Menck HR, Henderson BE. Cancer incidence patterns in the Pacific Basin. Natl Cancer Inst Monogr. 1982;62:101-109.

34. Haiman CA, Stram DO, Wilkens LR, et al. Ethnic and racial differences in the smoking-related risk of lung cancer. $N$ Engl J Med. 2006;354(4):333-342. doi:10.1056/NEJMoa033250

35. CotÚ ML, Kardia SL, Wenzlaff AS, Ruckdeschel JC, Schwartz AG. Risk of lung cancer among white and black relatives of individuals with early-onset lung cancer. JAMA. 2005;293(24):3036-3042. doi:10.1001/jama.293.24.3036

36. National Cancer Institute. Cancer Trends Progress Report 2014/2015 Update. Health Union, Philadelphia, PA, USA: 2015.

37. Jonsson B, Wilking N. The burden and cost of cancer. Ann Oncol. 2007; 18:8-22.

38. Gol-Montserrat J, Del Burgo MLM, Quecedo L, Del Llano JE. Analysis of productivity costs in cancer: a systematic review. Global Reg Health Technol Assess. 2017;4(1):grhta.5000262. doi:10.5301/grhta.5000262
ClinicoEconomics and Outcomes Research

\section{Publish your work in this journal}

ClinicoEconomics and Outcomes Research is an international, peerreviewed open-access journal focusing on Health Technology Assessment, Pharmacoeconomics and Outcomes Research in the areas of diagnosis, medical devices, and clinical, surgical and pharmacological intervention. The economic impact of health policy and health systems

\section{Dovepress}

organization also constitute important areas of coverage. The manuscript management system is completely online and includes a very quick and fair peer-review system, which is all easy to use. Visit http://www.dovepress.com/testimonials.php to read real quotes from published authors.

Submit your manuscript here: https://www.dovepress.com/clinicoeconomics-and-outcomes-research-journal 